Volume 01, No 02- Maret 2017

ISSN: 2582-1339(Print), ISSN: Dalam Proses (Online)

\title{
TANGGAPAN PETANI TERHADAP PEMASANGAN GUPON BURUNG HANTU DI KECAMATAN MOJOANYAR-KABUPATEN MOJOKERTO
}

\author{
RESPONDENT RESPONSE TO THE INSTALLATION OF GUPON BIRD HEALTH \\ IN MOJOANYAR DISTRICT - MOJOKERTO \\ Moch. Sodiq, Wilujeng dan Sutoyo \\ Fakultas Pertanian Universitas Pembangunan Nasional "Veteran “Jawa Timur \\ E - Mail : hmochsodiq@gmail. Com
}

\begin{abstract}
ABSTRAK
Di kelompok tani Sri Rejeki Desa Ngarjo dan Harapan Jaya Desa Wunut, Kecamatan Mojoanyar Kabupaten Mojokerto, pada bulan Agustus 2016 masing - masing telah dipasang tambahan gupon burung hantu sebanyak 4 buah dan 8 pangkringan. Pada bulan November Desember 2016 dilakukan evaluasi tanggapan petani terhadap pemasangan gupon burung hantu. Diambil sampel petani sebanyak 20 orang secara acak pada kelompok tani tersebut.Hasil evaluasi tanggapan petani menunjukkan bahwa ; 1). Sampai 60 hari pemasangan 8 gupon telah ditempati oleh burung hantu ;2). Serangan tikus menurun dari rata-rata $6 \%$ menjadi $0.70 \%$ dengan kerugian produksi per Ha tinggal Rp. 175.000 ; 3). Tingkat kepuasan petani sangat puas
\end{abstract}

Kata Kunci : Tanggapan, gupon, burung hantu.

\begin{abstract}
Farmer groups Sri Rejeki Ngarjo village and Harapan Jaya Wunut village subdistrict Mojoanyar, Mojokerto district in August 2016 has been installed each additional cage (gupon) owl 4 units and 8 seat (pangkringan). In November until Desember 2016 to evaluate the respondent of farmers to install gupon owl. Sample of farmer as manyas 20 peoples were taken random ly on farmer group Sri Rejeki and Harapan Jaya. Purpose of the evaluation was to asses to effectiveness of placement of an owl, rat attacks declime and loss of rice level of satisfaction of farmers. Results of the evaluation indicate that the response of farmers; 1 ). Up to 60 days of installation 8 gupon has been oceupied by owls ; 2) Attack of rat decreased from on everage of $6 \%$ to $0.70 \%$ with loss of production per Ha still IDR. 1.750.000. ;3). The level of satisfaction of farmers are very satisfied.
\end{abstract}

Key Words : Response, cage and owl

\section{PENDAHULUAN}

Pemanfaatan burung hantu (Tyto alba javanica) sebagai agensi pengendalian hayati tikus sawah memberikan harapan cukup baik di persawahan padi di Desa Wunut dan Desa Ngarjo selama 5 tahun (2011 - 2014), terbukti dengan semakin meningkatnya produksi padi dari puso menjadi $4-5$ ton gabah kering panen setiap hektar.Burung hantu dalam satu tahun mampu bertelur dua kali, yaitu pada bulan Mei sampai dengan Juni dengan periode 4,5
- 5 bulan sekali. Telur yang dihasilkan berjumlah $4-11$ butir, yang dikeluarkan selang dua hari dan dierami selama $30-34$ hari, dengan kemungkinan menetas $50 \%$. (Widodo, 2000). Kemapanan burung hantu (Tyto alba javanica) dalam suatu ekosistem sangat tergantung pada ketersediaanhabitat yang sesuai ( Mangundihardjo, 2003).

Habitat adalah tempat beserta komponen-komponennya dimana burung hantu dapat hidup dan berkembangbiak secara optimal (Anonim, 2010). 
Habitat adalah tempat beserta komponenkomponennya dimana burung hantu dapat hidup dan berkembangbiak secara optimal (Anonim, 2010). Habitat merupakan suatu daerah yang dapat menyediakan komponen utama bagi kemapanan suatu populasi Tyto alba javanica antara lain pakan (mangsa), tempat berlindung, air dan ruang. Mangsa sebagai sumber energy dan nutrisi merupakan komponen habitat yang paling penting. Ketersediaan pakan ditentukan oleh melimpahnya mangsa. Tenaga yang dikeluarkan saat memburu mangsa akan digantikan oleh kandungan energi tinggi dari hasil buruannya (Sodiq, 2001 ; Kuswardani,2009).

Burung hantu mempunyai kelebihan yaitu terbang dengan sayap tanpa suara guna mencegah mangsanya mendengar, dan membantu pendengarannya sendiri. Faktor-faktor yang mempengaruhi kemapanan burung hantu di ekosistem persawahan Kecamatan Mojoanyar Kabupaten Mojokerto belum pernah dikaji secara mendasar. Salah satu faktor tersebut adalah karakteristik habitat, antara lain mangsa, cover (pelindung), dan ruang. Dari ketiga habitat tampaknya penyediaan pelindung berupa gupon perlu ditingkatkan.Di kelompok tani Sri Rejeki sampai bulan Maret 2016 telah terpasang 6 gupon, sedangkan di kelompok tani Harapan Jaya sebanyak 9 gupon. Luas sawah di Desa Ngarjo (kelompok tani Sri Rejeki) 113.07 Ha dan Desa Wunut (kelompok tani Harapan Jaya) seluas 106,64 Ha. Sepasang burung hantu mampu melindungi tanaman padi seluas $5 \mathrm{Ha}$ dari serangan tikus (Purnama, 2009 ; Anonim, 2016) sehingga dilokasi sawah 2 kelompok tani diatas masih perlu ditambah gupon. Tujuan evaluasi tanggapan petani kelompok tani Sri Rejeki dan Harapan Jaya Kecamatan Mojoanyar, Kabupaten Mojokerto adalah untuk mengkaji efektifitas pemasangan gupon terhadap penempatan burung hantu, penurunan serangan tikus dan kerugian padi serta tingkat kepuasan petani.

\section{METODE PENELITIAN}

Pengkajian evaluasi dilakukan pada kelompok tani Sri Rejeki Desa Ngarjo, dan Harapan Jaya - Desa Wunut,Kecamatan Mojoanyar, Kabupaten Mojokerto mulai bulan Nopember Desember 2016. Pengkajian evaluasi menggunakan 2 ( dua ) perlakuan yaitu sebelum dan sesudah pemasangan gupon. Setiap kelompok tani yaitu Sri Rejeki dan Harapan Jaya masing - masing telah dipasang 4 gupon dan 8 pangkringan. Pemasangan gupon dilakukan pada saat awal tanam padi musim kemarau ( gadu ) bulan Agustus 2016. Sebelum dipasang tambahan gupon, di kelompok tani Sri Rejeki sudah terpasang 6 gupon dan kolompok tani Harapan Jaya 9 gupon. Metode penilitian menggunakan survei terhadap kelompok tani Sri Rejeki dan kelompok tani Harapan Jaya. Jumlah sampel dari masing - masing kelompok tani sebanyak 10 orang, diambil secara acak. Parameter yang diamati adalah : 1). Gupon yang ditempati burung hantu; 2). Serangan tikus dan kerugiannya; 3). Tingkat kepuasan petani setelah dipasang gupon burung hantu.

\section{HASIL DAN PEMBAHASAN}

\section{Penempatan Burung Hantu}

Berdasarkan pengamatan dilapang dengan melihat bekas sisa makanan bangkai tikus di 4 gupon kelompok tani Sri Rejeki dan 4 gupon di kelompok tani Harapan Jaya setelah 20 hari s/d 60 hari pemasangan, semua gupon (8 buah) sudah ditempati oleh pasangan burung hantu, Hal ini menunjukkan bahwa anakan burung hantu di lapang cukup banyak dan perlu tempat tinggal (gupon) baru.Anakan burung hantu setelah berumur 8 bulan akan membentuk keluarga baru dan tinggal pada sarang yang berbeda dengan induknya. Burung hantu mempunyai sifat setiap 
Sodiq dkk: Tanggapan Petani Terhadap Pemasangan Gupon....

pasangan tidak akan menempati gupon (sarang) yang telah ditempati oleh pasangan burung hantu lainnya.(Anonim, 2016).

\section{Serangan Hama Tikus dan Kerugiannya}

Hasil wawancara dengan petani di kelompok tani Sri Rejeki dan Harapan Jaya yang dipasang gupon burung hantu tentang serangan tikus dan kerugiannya disajikan pada tabel kerugiannya pada tabel 1 dan 2 berikut ini. Tabel 1 di bawah, menunjukkan bahwa sebelum dipasang tambahan 4 gupon dan 8 pangkringan baru, serangan tikus rata - rata sebesar $5,42 \%$ dengan taksiran kerugian gabah sebesar Rp. 1, 364,360 /Ha. Setelah dipasang tambahan gupon, serangan tikus pada tanaman padi menurun tinggal $0,12 \%$ dengan taksiran kerugian sebesar Rp. 78.320

Tabel 1. Hasil Evaluasi Serangan dan Kerugian Tikus di Kelompok Tani Sri Rejeki

\begin{tabular}{ccccr}
\hline \multirow{2}{*}{$\begin{array}{c}\text { No } \\
\text { Responden }\end{array}$} & \multicolumn{2}{c}{ Sebelum Dipasang Gupon } & \multicolumn{2}{c}{ Sesudah Dipasang Gupon } \\
\cline { 2 - 5 } & $\begin{array}{c}\text { Serangan Tikus } \\
(\%)\end{array}$ & $\begin{array}{c}\text { Kerugian Hasil } \\
\text { Padi } \\
(\mathrm{Rp} / \mathrm{Ha})\end{array}$ & $\begin{array}{c}\text { Serangan Tikus } \\
(\%)\end{array}$ & $\begin{array}{c}\text { Kerugian Hasil } \\
\text { Padi } \\
(\mathrm{Rp} / \mathrm{Ha})\end{array}$ \\
\hline 1 & 10,00 & 2.860 .000 & 0 & 0 \\
2 & 3,50 & 910.000 & 1,00 & 374.000 \\
3 & 3,50 & 910.000 & 0 & 35.200 \\
4 & 10,00 & 2.600 .000 & 0 & 0 \\
5 & 10,00 & 2.980 .000 & 0 & 0 \\
6 & 0,10 & 26.400 & 0 & 0 \\
7 & 0,10 & 27.200 & 0 & 0 \\
8 & 3,50 & 910.000 & 0,10 & 0 \\
9 & 10,00 & 1.510 .000 & 0 & 0 \\
10 & 3,50 & 910.000 & 0 & 783.200 \\
\hline Jumlah & 54,20 & 13.643 .600 & 1,20 & 78.320 \\
\hline Rata-rata & 5,42 & 1.364 .360 & 0,12 & 000 \\
\hline
\end{tabular}

Sumber: data Primer Diolah, 2016

Hal ini disebabkan adanya tambahan populasi burung hantu sebanyak 4 pasang 4 gupon), sehingga mampu menekan serangan tikus pada tanaman padi kelompok tani Sri Rejeki Desa Ngarjo Kecamatan Mojoanyar.Dengan adanya predator burung hantu, petani tidak lagi mengeluarkan biaya untuk pengendalian hama tikus disawah seperti gropyoken, pengomposan bele-rang dan pemasangan umpan beracun. Hasil evaluasi pemasangan gupon burung hantu dilahan sawah kelompok tani Hara-pan Jaya terlihat pada tabel di bawah ini. 
Tabel 2. Hasil Evaluasi, Serangan dan Kerugian Tikus di Kelompok Tani Harapan Jaya

\begin{tabular}{crrrr}
\hline \multirow{2}{*}{ No Responden } & \multicolumn{2}{c}{ Sebelum Dipasang Gupon } & \multicolumn{2}{c}{ Sesudah Dipasang Gupon } \\
\cline { 2 - 5 } & $\begin{array}{c}\text { Serangan } \\
\text { Tikus }\end{array}$ & $\begin{array}{c}\text { Kerugian } \\
\text { Hasil Padi ( Rp / } \\
\text { Ha })\end{array}$ & $\begin{array}{c}\text { Serangan Tikus } \\
(\%)\end{array}$ & $\begin{array}{c}\text { Kerugian } \\
\text { Hasil Padi ( Rp / } \\
\text { Ha })\end{array}$ \\
\hline 1 & 10,00 & 2.400 .000 & 1,00 & 300.000 \\
2 & 5,00 & 1.250 .000 & 1,00 & 346.000 \\
3 & 20,00 & 5.000 .000 & 5,00 & 340.000 \\
4 & 5,00 & 1.800 .000 & 0 & 0 \\
5 & 5,00 & 1.250 .000 & 1,00 & 350.000 \\
6 & 5,00 & 1.470 .000 & 2,00 & 704.000 \\
7 & 5,00 & 1.300 .000 & 1,00 & 360.000 \\
8 & 5,00 & 1.260 .000 & 1,00 & 346.000 \\
9 & 5,00 & 1.540 .000 & 0 & 0 \\
10 & 5,00 & 1.260 .000 & 1,00 & 330.000 \\
\hline Jumlah & 70,00 & 18.530 .000 & 13,00 & 2.730 .000 \\
\hline Rata- rata & 7,00 & 1.835 .000 & 1,30 & 273.000 \\
\hline
\end{tabular}

Sumber: data Primer Diolah, 2016

Tabel 2 di atas memperlihatkan juga, bahwa sebelum dipasang tambahan 4 gupon dan 8 pangkringan baru, serangan tikus di sawah kelompok tani Harapan Jaya rata-rata sebesar $7 \%$ dengan taksiran kerugian padi sebesar Rp. 1.853.000/Ha. Setelah dipasang tambahan gupon baru, serangan tikus pada tanaman padi turun menjadi $1,3 \%$ dengan taksiran kerugian sebesar Rp. 273.000/Ha. Penurunan serangan tikus cukup signifikan karna adanya tambahan populasi burung hantu sebanyak 4 pasang yang menetap disawah. Dengan tambahan populasi burung hantu tersebut populasi tikus menurun yang berakibat serangannya juga menurun dan pada gilirannya kerugian akibat serangan tikus juga menurun. Demikian pula di Desa Tlogowau, Kecamatan Guntur, Kabupaten Demak telah mengendalikan tikus menggunakan burung hantu. Hasilnya serangan tkus sawah yang semula setiap tanam padi mencapai $30 \%$ turun tinggal 1 $\%$ (Panggabean, 2012)

\section{Tingkat Kepuasan Petani setelah di Pasang Gupon}

Hasil wawancara tingkat kepuasan petani responden kelompok tani Sri Rejeki dan Harapan Jaya, tampak pada tabel berikut ini.

Tabel 3. Tingkat Kepuasan Petani Setelah Dipasang Gupon

\begin{tabular}{ccc}
\hline \multirow{2}{*}{$\begin{array}{c}\text { No } \\
\text { Responden }\end{array}$} & \multicolumn{2}{c}{ Kelompok Tani } \\
\cline { 2 - 3 } & Sri Rejeki & $\begin{array}{c}\text { Harapan } \\
\text { Jaya }\end{array}$ \\
\hline 1 & 3 & 3 \\
2 & 2 & 3 \\
3 & 2 & 3 \\
4 & 2 & 3 \\
5 & 2 & 3 \\
6 & 2 & 3 \\
7 & 2 & 3 \\
8 & 3 & 3 \\
9 & 2 & 3 \\
10 & 3 & 2 \\
\hline Jumlah & 23 & 29 \\
\hline Rata - rata & 2,3 & 2,9 \\
\hline
\end{tabular}

Keterangan : 1. Kurang Puas 2. Cukup

Puas 3. Sangat Puas

Sumber: data Primer Diolah, 2016

Tabel 3 diatas menunjukkan bahwa di kelompok tani Sri Rejeki tingkat kepuasan petani setelah dipasang gupon burung hantu $30 \%$ sangat puas dan $70 \%$ cukup puas sedangkan dikelompok tani Harapan Jaya 90\% sangat puas dan sisanya $10 \%$ cukup puas. Dengan demikian dapat 
dikatakan semua petani sangat puas (skor

2,6) setelah dipasang gupon burung hantu

\section{KESIMPULAN}

Berdasarkan hasil evaluasi, dapat disimpulkan sebagai berikut :

1. Sampai 60 hari setelah pemasangan gupon, seluruh gupon ( 8 buah ) telah ditempati oleh burung hantu

2. Serangan tikus menurun dari rata-rata $6 \%(5,42-7 \%)$ menjadi $0,70 \%(0,12$ $-1,30 \%$ ) dengan kerugian produksi padi tinggal Rp. 175,000/Ha

3. Tingkat kepuasan setelah dipasang gupon burung hantu sangat puas (skor 2,6

\section{DAFTAR PUSTAKA}

Anonim, 2009. Tikus Sawah ( Rattus argentiventer Rob \& Kloss ), BP.Padi. Litbang Deptan 2009

Anonim, 2016. Menengok Penangkaran Buarung Hantu di Kampung Gus Dur - Sinartani, Edisi 12 - 18 Oktober 2016, No.3674, Th XLVII. Hal.5.

Koeswardani, R. A. 2009. Keragaman Jenis Mangsa Burung Hantu Tyto alba javanica ( Gmel) Di Ekosistem Persawahan. Jurnal Pertanian dan Biologi Universitas Medan Area. Agrobio Vol 1 No.1.Mei 2009

Mangoendihardjo,S. 2003. Evaluasi Kemapanan dan Prospek Burung Hantu Tyto alba Dalam Pengendalian Tikus Di Perkebunan Kakao, Kelapa Segayung Utara, Batang. PSPH>UGM Jogyakarta

Panggabean, G. 2012. Tyto alba Ampuh Memberantas Tikus. Sinartani, Edisi. 15 - 20 Agustus 2012, No. 347,tahun XLII. Hal. 21.

Purnama,S. 2009. Menyelamatkan Serak Jawa ( Tyto alba ) di Tengah Pembangunan Gedung UNY.
Laporan Singkat Temuan Tyto alba javanica FMIPA. UNY

Sodiq,M. 2001. Pengelolaan Hama Tikus Sawah. Majalah Ilmiah Pembangunan Vol.X(23): 106 - 109. UPN “ Veteran “ Jawa Timur

Widodo,S.B.2000. Burung Hantu Pengendali Tikus . Penerbit Kanisius Jogyakarta. 